A CASE

or

\title{
MALIGNANT DISEASE OF THE THYROID GLAND,
}

WITH MOST UNUSUAL COURSE.

\author{
BY \\ FELIX SEMON, M.D., F.R.C.P., \\ PHYSIOIAN FOR DIBEASES OF THE THROAT TO ST. THOMAS'S HOSPITAL AND \\ THE NATIONAL HOSPITAL FOR EPILEPST AND \\ PARALYSIS, QUERN SQUARE.
}

Received February 13th-Read June 13th, 1893.

ON the 13th of January, 1891, I was consulted by Miss L-, æt. 52, sent to me by Dr. Wright of Huddersfield with the following history:

Miss L- had consulted Dr. Wright about six weeks previously, complaining of difficulty in respiration with much cough and expectoration; she had brought up a mouthful of blood for the first time the day previous to her visit. On examination Dr. Wright found a good deal of bronchial catarrh; externally a swelling at the right side of the thyroid was seen, which seemed solid and fixed. During the time of his attendance no appreciable altera 
tion in its size took place, and under treatment everything settled down except the difficulty in respiration, which he believed was entirely due to pressure caused by the enlargement. Internal and local iodine treatment having failed to reduce the latter, Dr. Wright felt that nothing short of the removal of the right lobe of the thyroid was likely to be of any benefit.

When Miss L- consulted me on the 13th January the external conditions entirely corresponded to Dr. Wright's description. There was a very hard but not very large tumour about the size of a Tangerine orange to be felt in the region of the right lobe of the thyroid, rather fixed to the larynx, but the skin above it was moveable. It caused no pain and no inconvenience in swallowing, and in fact she was hardly aware of its existence. Her voice was perfectly normal and clear, but occasionally, especially after speaking a little, the inspiration was very stridulous.

On laryngoscopic examination I was not a little startled to see at the first glance below the vocal cords, and much more developed towards the left side-that is to say, to the side opposite the external tumour-a large whitish ulcerating swelling, which on its extremity on the left seemed to nearly reach up to the level of the left vocal cord. It was completely covered by the vocal cords on phonation, and the mobility of the cords was perfectly unimpaired. When, however, the patient inspired deeply one saw that this growth to a very great extent filled the subglottic cavity, and the dyspncea thus was certainly only in part due to the pressure of the external tumour, the greater share being taken by the internal narrowing. When I looked with the laryngoscope for the second time the tumour without any apparent cause actually began to bleed, though the hæmorrhage was only insignificant.

There could not be the least doubt in my mind after this that one had to do with a malignant growth, the question being whether it had started from the subglottic cavity, and on the one hand extended upwards to the left, on the other broken through the crico-thyroid membrane 
on the right and invaded the right lobe of the thyroid gland; or whether the whole affection had started from the thyroid gland itself, and the invasion of the subglottic part of the larynx was only a secondary phenomenon.

This question of course could only be elucidated at a later period by microscopic examination of the growth itself. Therapeutically there could, in my opinion, seeing the large extent of the growth, not be the least doubt that the case was not suitable for any radical operation, and that the only proper measure could consist in the performance of early tracheotomy. Mr. Butlin, who subsequently saw the patient in consultation with me, entirely shared my views. I then wrote to Dr. Wright, and advised early tracheotomy, the condition being in my opinion distinctly dangerous, inasmuch as the least access of acute œdema, which so often supervenes in cases of this sort, would in all probability have been directly fatal by complete occlusion of the trachea. The patient returned to Huddersfield, and Dr. Wright having approved of my proposition, came again up to town on the 16th January.

On the following morning I performed low tracheotomy, assisted by Messrs. Miller and Carstairs of St. Thomas's Hospital, Mr. Tyrrell giving chloroform. I of course selected the lower operation in order to be as far as possible away from the seat of the disease. The operation did not offer the least difficulty, but when the trachea was laid bare it was seen that it was already to some extent pushed towards the left, whilst at the same time it was found that the right carotid had been displaced backwards and outwards, and was very distinctly felt pulsating just behind the external tumour.

The patient at first made an excellent recovery, and the temperature never rose during the first week, but already at that time two very uncommon symptoms made their appearance. In the first place the patient brought up two or three times within the twenty-four hours with great difficulty, and only after much coughing and strain- 
ing, a brownish-red, sometimes round, sometimes oval mass of a tenacious, leathery character, varying from the size of a hazel-nut to that of a small cherry, altogether unlike any bronchial secretion I have ever previously seen. These big lumps usually obstructed before being expelled the opening of the tube, and caused for the time being considerable dyspnœa; as a rule they could only be removed with great difficulty. In the free intervals the breathing was absolutely quiet, and there was not the least symptom of general bronchitis or of localised pneumonia, the temperature remaining normal all the time. The attacks of coughing, howerer, which preceded the expulsion of these lumps, always exhausted the patient very much.

The second phenomenon was equally curious. The patient's voice, which, previous to the operation, had been perfectly normal, after the operation varied in the most extraordinary manner : sometimes it was just as normal as previous to the operation; at other times it was not only absolutely aphonic, but the patient could not produce any sound at all, and one had certainly the impression that on attempting to speak she was seized with a spasm of the glottis. On laryngoscopic examination no clue was detected of the cause of this curious phenomenon, both cords being perfectly white, and moving with complete freedom.

Whilst with the exception of these two symptoms the recovery and the healing of the wound made very satisfactory progress, suddenly on Saturday, the 24th, i. e. a full week after the operation, an unfavorable change occurred. The patient had from the Friday to the Saturday a bad night, owing to much coughing, and when I saw her on Saturday morning was much exhausted. Careful examination failed to elicit any definite change. When I came, however, in the evening of the 25th I found her very feverish, the temperature without any rigor having gone up to $101.4^{\circ}$, the pulse to 120 , and at the same time very considerable cardiac disturbance had occurred; the heart's action was 
absolutely irregular, a series of quick beats would besuddenly followed by a shorter or lesser complete stop; then there would be sometimes many, sometimes few quick beats, again a pause, again one or two beats, again a pause, a series of beats, \&c. In a word no type in the irregularity could be detected. In the afternoon of the same day also a sort of general breathlessness had made its appearance, totally different from the previous choking attacks due to the obstruction caused by the large pellets of secretion. There was no lividity, and the breathing was by no means unduly hurried, the respirations being about twenty-four a minute.

Considering these curious phenomena, I came to the conclusion that all of them were probably to be attributed to one and the same cause, viz. to irritation of the right pneumogastric nerve in consequence of pressure of the growth; the general breathlessness, rise of temperature, and the curious expectoration being due to irritation of the pulmonary branches, the change in the voice to. irritation of the laryngeal, and the irregularity of the heart's action to irritation of the cardiac branches. I gave the patient digitalis, acetate of iron, and tincture of valerian. On the morning of the 26 th the temperature had fallen to $98.8^{\circ}$, but the same night it again rose to $100.8^{\circ}$, and in the course of the 27 th it gradually went up to $102 \cdot 5^{\circ}$. On the 28 th in the morning it fell to $99 \cdot 4^{\circ}$, and in the evening to the normal ; on the afternoon of that day I had a consultation with Dr. Broadbent, who carefully examined the patient and did not find any definite lesion anywhere. He entirely shared my opinion that all phenomena were due to irritation of the pneumogastric nerve. He also approved of the treatment pursued.

Within the next week a steady and pleasing improvement took place, and the temperature remained normal. The cardiac irregularity slowly but steadily got better under the influence of digitalis, though a very distinct systolic murmur equally slowly developed, which certainly had not been present previous to the cardiac attack. 
The voice also gradually got better, and the patient, as a rule, when closing the opening of the tube with her finger could speak in her normal voice, though occusionally still the attacks of spasm of the glottis combined with aphonia were present. The only thing which did not show much change was the expectoration. Still twice or three times daily the brownish-red lumps were expectorated, but even those on the whole were less tenacious than formerly, and were expelled with less difficulty. Once or twice the patient had an attack of general breathlessness, but not so intense as on the first occasions. On Wednesday, the 4th of February, she for the first time drove out a little, and this was repeated on the following days. Her general health meanwhile considerably improved. On Friday Dr. Wright came to town, and a consultation having taken place between him and me on Saturday, the patient on the same day left under his aharge for Huddersfield, wearing a rectangular (Durham's) silver tracheotomy tube.

During the first part of the year I occasionally heard from Dr. Wright that the patient was very slowly but steadily losing ground without any new symptoms having made their appearance. From July till the end of November I heard nothing more, and had already intended to write to Dr. Wright and ask him for further particulars about the case, which I had little doubt would have ended fatally before that time, when to my great surprise I received in the last days of November a letter from the patient herself, asking for an appointment on the 27th of that month, and which letter was followed by another from Dr. Wright, in which he informed me that he was much interested to know my opinion of her case. The disease during the summer months had seemed somerhat in abeyance. There had been no hæmorrhage and very wuch less expectoration than formerly. The general emaciation, however, had seemed to steadily continue, and the general outlook seemed dark.

When the patient entered my room on the $27 \mathrm{th}$ of 
November I was first of all struck with the very considerable emaciation which had taken place since I had last seen her in February ; and secondly, with the absolute clearness and natural character of her voice-a circumstance which seemed the more striking, as already in February the intra-tracheal growth had apparently reached up to nearly the level of the left vocal cord. On inquiries I learned that there had been absolutely no pain, no dysphagia, no difficulty in breathing; the breath had never been fœtid, there had been no expectoration of more solid particles, and that the only but great trouble was the constant wearing of the tube, which, according to the patient's statements, made her life a misery. Expectoration through it she stated to be exceedingly difficult and tiresome, and according to her assertion her life was mostly spent in removing and putting in the internal tube.

On external examination it was seen that the emaciation of the face extended to the body in general; the tumour on the right side of the neck was considerably larger than it had been in February, and was now the size of an average apple. It was exceedingly hard, slightly moveable in the direction from behind forward, and vice versâ, but not in the direction from above downward, and was apparently continuous with the trachea. It was not tender on pressure, the skin over it. could be freely moved, and there were no enlarged glands in its neighbourhood, or indeed anywhere in the neck to. be felt. Condition of the lungs and heart normal.

On laryngoscopic examination I hardly trusted my eyes when I saw that the subglottic tumour which Mr. Butlin, Dr. Wright, and I had so clearly seen (I myself on a good many occasions) had completely disappeared, and that it was now possible to see a long way down into the trachea. There, corresponding to the external tumour on the right side, a very considerable inward bulging was seen on the right side, a smaller one bulging forward the posterior wall, and again at the same level another 
smaller one slightly bulging in the left lateral wall of the tube. On the border of the right lateral and posterior swellings two irregular little knobs could be seen; otherwise the mucous membrane covering these bulgings appeared to be tolerably smooth, and there was at any rate no evidence of deep ulceration. Whether these projections represented mere in ward bulgings of the walls of the trachea, or actual intra-tracheal growths, it was impossible to decide.

From the observations of the patient herself and of a sister of hers who accompanied her I made out that the correctness of the diagnosis arrived at at the beginning of the year was more than doubted by them, and that the family had become almost convinced that the tumour was of a benign nature and could be removed, thereby abolishing the pressure upon the windpipe, and enabling the patient to dispense with the tracheotomy tube, the latter object being apparently the one on which all her thoughts were concentrated. I at once wrote to Dr. Wright, and whilst fully admitting the very unusual features of the case, such as the surprisingly long duration of life, the absence of pain, cachexia, dysphagia, enlargement of glands in the neck, and-above all-the disappearance of the intra-tracheal growth, which ten months previously had formed the most prominent feature of the case; nevertheless considering the history-the progressive emaciation of the patient, the increase in size of the external tumour, and the undoubted fact that at one period of the illness there had been an ulcerating tumour in the trachea-I could not alter my original opinion.

After the result of my examination I had spontaneously offered the patient another consultation with Mr. Butlin. The patient and her sister, however, seemed to be anxious to have previous to this another perfectly independent opinion, and mentioned $\mathrm{Dr}$. Greville Macdonald as consultant. To this proposal I at once consented ; stipulating only that the patient should give him a full history of her 
case, because the present appearances alone without the aid of such history would hardly enable anybody to come to a definite opinion. Dr. Macdonald saw Miss L- on the 28th, and from the result of his examination and from what the patient told him (the description, as we afterwards found, was a very incomplete one indeed) very naturally came to the conclusion that the tumour in all probability was merely a hard goitre pressing upon the trachea, and that an attempt could well be made to remove it.

On the following day a consultation took place between Mr. Butlin, Dr. Greville Macdonald, and myself. Mr. Butlin's view was almost identical with my own. He stated that he had never seen a benign tumour of the thyroid gland of such extreme hardness. He laid great stress upon the internal swelling on the left side of the trachea, and he declared that he would not undertake even an exploratory operation with a view to radical removal, because the danger of such exploratory operations was great, and he felt that it would not be possible to finish the operation.

When Dr. Macdonald heard the full previous history of the patient he stated that his opinion thereby of course became considerably modified, but still he said that if he were the patient himself he would run the risk of an exploratory operation. I held to my first opinion.

In view of this conflict of opinions we all agreed that Miss L- ought to see another surgeon, and that Sir William MacCormac should be consulted. Sir William examined the patient without knowing anything of her previous history. He too considered the goitre exceedingly hard, uncommonly so for a benign growth; he also found that whilst freely moveable in the direction from the front backwards, it was not so in an up and downward direction, and above all that it was very firmly attached to the trachea and could not be separated from this at all, but still he considered an exploratory operation feasible. When he afterwards heard the full history of the case he 
looked more gravely upon the chances of an operation than before, but still considered it justified, seeing the urgent wish of the patient and the sad prospect anyhow. He consented to make such an exploratory operation, warning Miss $\mathrm{L}$ - at the same time that it was impossible to foresee whether the operation could be completed at all, and plainly told her that under all circumstances it would be dangerous. Miss $\mathrm{L}$ - then once more asked my own opinion, when I simply told her that she must now decide for herself, that my own opinion was not shaken, but that $I$ admitted that the case was most unusual in several respects, and that I did not wish to debar her from taking what possibly was her only chance.

Miss L- decided to undergo the operation, and on December 19th, 1891, it was performed by Sir William MacCormac, Mr. Priestley, Mr. Robinson, and Mr. De Méric assisting, and Mr. Tyrrell giving chloroform, whilst Dr. Greville Macdonald, Dr. Wright, who came on purpose from Huddersfield, and I were present.

The first part of the operation presented no difficulty ut all, and indeed the tumour on all its aspects except the tracheal shelled out so easily from the surrounding structures, and looked so entirely like a common fibrous goitre, that all the time I could not help asking myself whether it was after all possible that the tumour was really only an uncommonly hard but otherwise innocent goitre, and whether Mr. Butlin and I might not have been deceived in what we originally had seen. However, when the operation had arrived at that stage that the tumour was merely to have been separated from the trachea, this was found to be impossible, as they were inseparably connected with, and indeed contiguous to, one another. Sir William had therefore to be satisfied with merely removing the external portion. The knife on cutting through the tumour made a loud grating noise, and when the external portion was removed, it was found to represent a hard fibrous goitre, containing several cysts with calcareous walls within itself, and having undergone in 
its central portion, where it was contiguous with the trachea, an obvious malignant degeneration, this part of the tumour being distinguished even to the naked eye by its colour and appearance from the surrounding merely hyperplastic portions. Rather free parenchymatous hæmorrhage followed the removal of the external portion, which was finally stopped by the application of Penghawar wool.

The patient recovered from the operation without any incident whatsoever. Microscopic examination of the growth made by $\mathrm{Mr}$. Shattock showed that it was an encephaloid carcinoma, starting from the gland cells themselves.

About a fortnight after the operation Sir William requested me to see the patient again. He had found a sort of " moveable velum" hanging down from the upper border of the opening in the air-tabe, which he thought acted as an imperfect valve obstructing the expiratory current, and he wished my opinion thereon, as the patient's urgent wish, viz. to dispense with her tube, could not be complied with so long as this obstruction existed.

I saw Miss L- on January 4th of the present year, when I found her even more emaciated than a fortnight ago, but otherwise still in-comparatively speaking-surprisingly good condition. Her voice was still perfectly clear, there was no dysphagia, no pain, and she stated that she could breathe better; a statement which was corroborated by the nurse, though it was not easy to understand how the partial removal of a tumour situated above the tracheotomy tube could have relieved the breathing, unless this had exercised some pressure upon the pneumogastric nerve, of which of late there had been no proof whatever. The external wound had not yet healed, there being a deep sinus, which was kept plugged with iodoform gauze. On removal of this it was seen that the wound was granulating freely. On examination with a good light through the tracheotomy wound I found a projection corresponding to Sir William MacCormac's description hanging down from the right lateral wall voL. LXXVI. 
into the trachea and down to close to the upper border of the tracheotomy wound. Its surface, however, was distinctly ulcerated-a fact of which Sir William by my wish convinced himself. It was, as he had previously found, slightly mobile, but certainly gave the probe with which I tried to move it upwards a sensation as if it possessed a good deal of weight. I introduced a small mirror into the wound, but could not look round the projection. My opinion of this projection was that it could be only one of two things, viz.-

1. An undermined, infiltrated, and ulcerating part of tracheal mucous membrane lifted from its base through the underlying ulcer, or-

2. The lower surface of a projecting part of the cancer itself. The second possibility I considered as by far the more likely one of the two.

Sir William, Mr. Priestley and I discussed the advisability or otherwise of removing this, but were unanimously against it, inasmuch as it was impossible to decide its exact nature and extent ; further, as the danger of hæmorrhage from it into the trachea undoubtedly was great, especially after our experience of the external wound during Sir William's operation a fortnight previously.

This was the last occasion when I saw the patient. She returned shortly afterwards to Huddersfield. The external wound gradually closed completely, and she again recovered, I was informed by Dr. Wright, to such a surprising degree from the operation that as late as September last she travelled, during the Leeds Musical Festival, every day from Huddersfield to Leeds and back.

Shortly after this, however, the external growth again rapidly increased, breathlessness became a prominent symptom, and from time to time smart hæmorrhages occurred.

On January 9th Dr. Wright made the following note in his case-book :- Complete aphonia, external growth much increased in size."

On January 11th "I was called up in the middle of the night, and found her suffering from a severe attack of 
hæmorrhage, which ultimately yielded to ice suction and Tinctura Hamamelis, mxx every hour.".

On the 12th "there was a return of hæmorrhage, and the pulse was intermittent."

On the 13th " in the afternoon hæmorrhage came on very violently, the tube was changed constantly, but with no relief. I could hear the flapping of something at the bottom of the tube. Patient apparently suffocating. As a last resource $I$ introduced a celluloid tube connected with a strong suction syringe, and tried the effects of strong suction. Nothing came, but the tracheotomy tube on the withdrawal of the other became suddenly blocked, and I thought the end had come. Suddenly, with a violent expulsive effort, a piece of the growth was shot out on to the bed, and the patient, half dying, suddenly became easy. This improvement continued until the 24th, when there was a return of the hæmorrhage."

"On the 25th I saw her twice during the day, and felt sure that matters would soon reach a crisis. The breathing was laboured, and the same flapping noise could be heard. I was called to her at 2 a.m., and she died at 3.20 a.m. from suffocation produced by a not to be restrained hæmorrhage. So much for the last history. As a matter of personal interest I may mention that Miss L- showed the same marvellous fortitude and entire unselfishness up to the very last, and thanked me personally in writing quarter of an hour before her death."

Post-mortem.- "This was only a modified one, having strict relation to the affected parts. I made an incision from the chin to the middle of the sternum, cut through the cartilages of the ribs, and sawed through the sternum rather below the middle. I made an effort in removing the larynx and trachea to include the external growth, but it was intimately adherent to the skin, was of the consistence of very ripe cheese, and broke down on the slightest touch.

"The larynx and trachea being removed, I slit them up on the anterior surface, going through the old tracheotomy 
wound. I then carefully examined the bronchial glands, but found no enlargement whatever. This done, I dissected the pneumogastric nerve on the right side down to its expansion at the root of the lung, and found that it was in no wise involved." So far Dr. Wright.

Of the larynx and trachea which you see before you, the following description is kindly given by Mr. Shattock.

"The thyroid gland is the seat of a malignant new formation, which extends backwards from the right side between the upper part of the trachea and the csophagus, in which situation it passes beyond the middle line and approaches closely to the left lobe of the gland, but without being actually continuous with it ; the growth as it lies on the right side of the cricoid cartilage and trachea has a vertical measurement of about $4 \mathrm{~cm}$.

"Into the upper part of the trachea there projects a broadly pedunculated slightly lobular process of the tumour $4 \mathrm{~cm}$. in length, and of a diameter so as to completely fill the canal : its surface is smooth and its texture extremely soft. The pedicle of the intra-tracheal process measures in the vertical direction $2 \mathrm{~cm}$., and is continuous with the thyroidal growth through the right and posterior walls of the trachea. The summit or highest border of the growth within the trachea is $5 \mathrm{~cm}$. below the level of the lower border of the cricoid cartilage.

"Above this there hangs into the canal, by a slender pedicle, a second smaller tumour; with its stalk this measures $1.5 \mathrm{~cm}$. in length, and appears as a clubbed or pyriform process $\cdot 7 \mathrm{~cm}$. in extreme breadth. Its exact site of attachment is $1 \mathrm{~cm}$. below the lower edge of the posterior border of the cricoid cartilage, and it is separated by a distinct interval of normal mucous membrane from the upper limit of the pedicle of the larger growth. The posterior wall of the trachea, for a distance of $3 \mathrm{~cm}$., is bulged forwards by the growth before referred to as lying between this tube and the cesophagus, and it is over this, exactly in the middle line, that the pedicle of the lesser intra-tracheal growth is attached. 
"Immediately on the right of the pedicle is a ragged soft tag of tissue, somewhat larger than it, and suggesting that a third process of the growth has at some time been detached."

Remarks.-The foregoing description of what I do not hesitate to say has been the most extraordinary case in my practice speaks for itself. I cannot sufficiently thank Dr. Wright for having procured the specimen, for I strongly feel that without an actual demonstration of this my description might justly have been received with some scepticism. The total disappearance of a comparatively big ulcerating growth in the trachea, without leaving any obvious traces of its existence on the mucous membrane from which it sprang, constitutes, so far as my knowledge goes, a hitherto undescribed phenomenon in tracheal pathology, and its occurrence would have remained somewhat inexplicable if not fortunately we had found at the post-mortem the upper and smaller ulcerating growth hanging down by a thread-like pedicle from the wall of the trachea. Just as this growth, which I am able to confidently say did not exist at the time when Mr. Butlin, Dr. Greville Macdonald, and I last examined the patient laryngoscopically, would not have left the least appreciable trace of its existence if its pedicle had sloughed close to its base, nothing now can be more natural, in view of the present condition of things, than to assume that a similar growth, only larger and higher up, existed when the patient first came to see me, and that it had sloughed away when she came up again in November, 1891. Mr. Shattock's final remark directly favours this hypothesis. Under all circumstances, however, it will remain a matter of curious interest and importance that, fully ten months after the existence of an ulcerating tumour in the windpipe definitely established by three observers, justifiable doubts as to the malignant nature of the disease could have arisen in the minds of two other competent authorities. In this respect the case certainly teaches a most important lesson. 
The fact that Dr. Wright at the post-mortem examination found the pneumogastric nerve in no wise affected makes, of course, the occurrence of the curious phenomena observed after the tracheotomy even more obscure. Still I am inclined to refer them, if not to actual affection, yet to irritation of that nerve, and would draw attention in that respect to the observation that at the time of the tracheotomy the right carotid had been displaced backwards and outwards, and was felt pulsating very distinctly behind the external tumour. It is but fair to assume that the right vagus, too, might have been at that time stretched and irritated.

Finally, I wish to draw attention to the remarkable fact that this originally infiltrating tumour became pedunculated, as shown by both the projections now visible in the trachea, as soon as it extended into the lumen of the tube. This appears to be not a peculiarity of this case, as I have already on a previous occasion described, ${ }^{1}$ together with Mr. Shattock, a case of sarcoma of the thyroid, which became pedunculated on its perforating the trachea. This would seem to be an important fact, which Mr. Shattock suggests may be explained by the growth meeting with no resistance as soon as it extends into an open tube.

1 'Transactions of the Pathological Society,' vol. xxxix, 1888, p. 42.

(For report of the discussion on this paper, see ' Proceedings of the Royal Medical and Chirurgical Society,' Third Series, vol. v, p. 126.) 


\section{DESCRIPTION OF PLATE VI.}

\section{A Case of Malignant Disease of the Thyroid Gland with most unusual course (Dr. Felix Semon).}

The drawing shows the extension of the thyroid growth into the trachea, occurring in the form of two pedunculated tumours, which are separated from one another by a distinct interval of normal mucous membrane. Close to the base of the upper tumour is a rag of tissue, which probably formed the base of the pedicle of a third tumour, which sloughed away and completely disappeared during the patient's life. 
Plate VI. Med. Chir. Trans Vol. LXXVI,

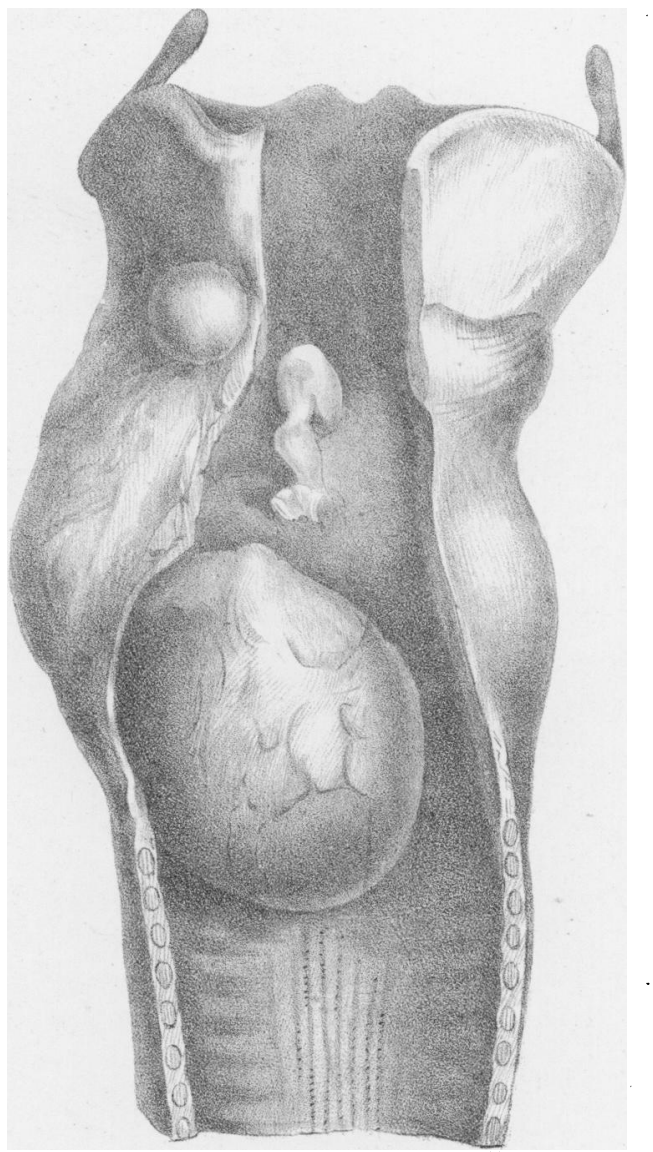

